\title{
ARTICLE
}

Received 11 Feb 2015 | Accepted 30 Jul 2015 | Published 8 Sep 2015

DOI: $10.1038 /$ ncomms 9238

OPEN

\section{Ambipolar solution-processed hybrid perovskite phototransistors}

\author{
Feng $\mathrm{Li}^{1}$, Chun Ma${ }^{1}$, Hong Wang ${ }^{1}$, Weijin $\mathrm{Hu}^{1}$, Weili $\mathrm{Yu}^{1}$, Arif D. Sheikh ${ }^{1} \&$ Tom $\mathrm{Wu}^{1}$
}

Organolead halide perovskites have attracted substantial attention because of their excellent physical properties, which enable them to serve as the active material in emerging hybrid solid-state solar cells. Here we investigate the phototransistors based on hybrid perovskite films and provide direct evidence for their superior carrier transport property with ambipolar characteristics. The field-effect mobilities for triiodide perovskites at room temperature are measured as $0.18(0.17) \mathrm{cm}^{2} \mathrm{~V}^{-1} \mathrm{~s}^{-1}$ for holes (electrons), which increase to 1.24 (1.01) $\mathrm{cm}^{2} \mathrm{~V}^{-1} \mathrm{~s}^{-1}$ for mixed-halide perovskites. The photoresponsivity of our hybrid perovskite devices reaches $320 \mathrm{AW}^{-1}$, which is among the largest values reported for phototransistors. Importantly, the phototransistors exhibit an ultrafast photoresponse speed of less than $10 \mu \mathrm{s}$. The solution-based process and excellent device performance strongly underscore hybrid perovskites as promising material candidates for photoelectronic applications.

\footnotetext{
${ }^{1}$ Department of Materials Science and Engineering, Division of Physical Sciences and Engineering, King Abdullah University of Science and Technology, Thuwal 23955-6900, Kingdom of Saudi Arabia. Correspondence and requests for materials should be addressed to F.L. (email: feng.li@kaust.edu.sa) or to T.W. (email: tao.wu@kaust.edu.sa).
} 
$\mathrm{M}$ ethylammonium lead halide $\left(\mathrm{CH}_{3} \mathrm{NH}_{3} \mathrm{PbX}_{3}, \mathrm{X}=\right.$ halogen $)$ perovskites have been intensively pursued as lightharvesting materials in high-performance hybrid solidstate photovoltaic devices ${ }^{1-13}$. This class of materials was first discovered by Weber nearly 36 years ago $^{14}$, and Mitzi and co-workers further revealed that halide perovskites combine the favourable carrier transport of inorganic semiconductors with the facile processing of organic materials ${ }^{15}$. In their pioneering work on field-effect transistors using hybrid perovskite $\left(\mathrm{C}_{6} \mathrm{H}_{5} \mathrm{C}_{2} \mathrm{H}_{4} \mathrm{NH}_{3}\right)_{2} \mathrm{SnI}_{4}$ as channels, a high on/off ratio of $10^{4}$ and a hole mobility of $0.6 \mathrm{~cm}^{2} \mathrm{~V}^{-1} \mathrm{~s}^{-1}$ were reported ${ }^{16}$. The recent successes of halide perovskites in photovoltaic technologies can be primarily ascribed to their suitable, direct bandgap with large absorption coefficients and low-cost solution-based processing, as well as their excellent transport properties ${ }^{17-20}$. Long electron-hole diffusion lengths and carrier lifetimes have also been observed in perovskite films, indicating low recombination rates of charge carriers ${ }^{21,22}$. The properties of these emerging materials also led to photoelectronic applications, such as electrically pumped lasers, light-emitting diode/ transistors and photodetectors ${ }^{23-31}$. Supplementary Table 1 summarizes the recent progresses on developing perovskite-based photodetectors. These hybrid perovskites can also be envisioned as good candidates for phototransistor, in which the gate bias, in addition to the incident light, is used as an additional parameter to modulate the channel transport ${ }^{32,33}$. Various types of semiconductors have been investigated as channel materials in phototransistors, such as $\mathrm{Si}$, III-V semiconductors, $\mathrm{ZnO}$, carbon nanotubes, quantum dots, organics and two-dimensional materials ${ }^{34-49}$. To date, there have been some pioneering lines of work on utilizing $\mathrm{CH}_{3} \mathrm{NH}_{3} \mathrm{PbX}_{3}$ as the active component in phototransistor-type devices ${ }^{27,29,30}$. However, the performance of these devices, particularly channel mobility and gate tuning, needs improvements.

In this work, we report on the fabrication and characterization of phototransistors on the basis of solution-processed organolead triiodide $\left(\mathrm{CH}_{3} \mathrm{NH}_{3} \mathrm{PbI}_{3}\right)$ and mixed-halide $\left(\mathrm{CH}_{3} \mathrm{NH}_{3} \mathrm{PbI}_{3-x} \mathrm{Cl}_{x}\right)$ perovskite films. The effects of gate voltage and light illumination on the transport of the perovskite channels were investigated. We found that these phototransistors exhibit clear ambipolar carrier transport characteristics, that is, they work in both accumulation (p-type) and inversion (n-type) modes. Highly balanced photoinduced carrier mobilities of $0.18 \mathrm{~cm}^{2} \mathrm{~V}^{-1} \mathrm{~s}^{-1}$ (holes) and $0.17 \mathrm{~cm}^{2} \mathrm{~V}^{-1} \mathrm{~s}^{-1}$ (electrons) were observed for $\mathrm{CH}_{3} \mathrm{NH}_{3} \mathrm{PbI}_{3}$, which increase to $1.24 \mathrm{~cm}^{2} \mathrm{~V}^{-1} \mathrm{~s}^{-1}$ (holes) and $1.01 \mathrm{~cm}^{2} \mathrm{~V}^{-1}$ $\mathrm{s}^{-1}$ (electrons) for the doped variant $\mathrm{CH}_{3} \mathrm{NH}_{3} \mathrm{PbI}_{3-x} \mathrm{Cl}_{x}$. As an important figure-of-merit for phototransistors, the photoresponsivity $(R)$ of our perovskite phototransistor reaches $320 \mathrm{~A} \mathrm{~W}^{-1}$. Furthermore, we observed that the phototransistors exhibit an ultrafast photoresponse time of less than $10 \mu \mathrm{s}$. The results indicate that solution-processed hybrid perovskites are very promising materials for constructing high-performance phototransistors, and they warrant exploration for use in other photoelectronic applications.

\section{Results}

Hybrid perovskite phototransistor. A schematic device structure of a bottom-gate, top-contact hybrid perovskite $\mathrm{CH}_{3} \mathrm{NH}_{3} \mathrm{PbI}_{3}-$ based phototransistor is illustrated in Fig. 1a. A heavily n-doped $\mathrm{Si}$ wafer with a $300-\mathrm{nm} \mathrm{SiO}_{2}$ surface layer (capacitance $\left(C_{\mathrm{i}}\right)$ of $15 \mathrm{nF} \mathrm{cm}^{-2}$ ) was employed as the substrate. The perovskite films were grown using the two-step vapour-assisted solution process $^{11}$, and the experimental details are given in the Methods section. In our devices, we coated poly(methyl methacrylate) (PMMA) as the protective layer on top of the perovskite channel to prevent the diffusion of moisture and/or atmospheric oxygen $^{21}$. In optimizing phototransistor devices, the semiconducting channel thickness is a key parameter. On the one hand, if the semiconducting channel is too thin, it will not absorb sufficient $\operatorname{light}^{10}$. In addition, pinholes in the thin perovskite films will cause inhomogeneous conduction in the channel. On the other hand, if the film is too thick, light from the top may not be able to penetrate the whole film, and the bottom gate will not effectively modulate the channel. In our work, the thickness of the $\mathrm{CH}_{3} \mathrm{NH}_{3} \mathrm{PbI}_{3}$ film prepared in the phototransistors is optimized at $100 \mathrm{~nm}$, as characterized using atomic force microscopy $(\mathrm{AFM})^{50}$. The detailed AFM measurement results are shown in Supplementary Fig. 1.

Figure $1 \mathrm{~b}$ shows the light absorption data of the $\mathrm{CH}_{3} \mathrm{NH}_{3} \mathrm{PbI}_{3}$ film. For this measurement, the thin films were prepared on a glass substrate using the same processing parameters as those used in fabricating the phototransistors. The strong and broad absorption in the ultraviolet and visible-light range, particularly from 400 to $760 \mathrm{~nm}$, reveals that the perovskite layer is a good light absorber. Furthermore, the absorption edge for the perovskite film is very sharp, suggesting a direct bandgap nature $^{7,18}$. Overall, the direct bandgap of $1.53 \mathrm{eV}$ and the favourable light absorption properties make perovskite $\mathrm{CH}_{3} \mathrm{NH}_{3} \mathrm{PbI}_{3}$ films very promising materials for constructing high-performance phototransistors.

Characterizations of the perovskite thin films. To investigate the crystallinity and microstructure of the perovskite thin films, X-ray diffraction (XRD) measurements were carried out. Figure 1c shows the $\mathrm{X}$-ray diffraction pattern of the as-prepared $\mathrm{CH}_{3} \mathrm{NH}_{3} \mathrm{PbI}_{3}$ film on a $\mathrm{SiO}_{2} / \mathrm{Si}$ substrate. Strong peaks at $14.08^{\circ}$, $28.41^{\circ}, 31.85^{\circ}$ and $43.19^{\circ}$ can be assigned to (110), (220), (310) and (330) diffractions of $\mathrm{CH}_{3} \mathrm{NH}_{3} \mathrm{PbI}_{3}$, respectively, indicating that the halide perovskite films possess the expected orthorhombic crystal structure with high crystallinity ${ }^{17}$. Notably, the absence of a diffraction peak at $12.65^{\circ}$ suggests that the level of the $\mathrm{PbI}_{2}$ impurity phase is negligible ${ }^{11}$. The surfaces of the perovskite $\mathrm{CH}_{3} \mathrm{NH}_{3} \mathrm{PbI}_{3}$ films were further evaluated via scanning electron microscopy (SEM) and AFM measurements. Figure 1d shows the surface morphology of the as-grown perovskite thin film grown on the $\mathrm{SiO}_{2} / \mathrm{Si}$ substrate. The perovskite film appears smooth without pinholes, and the uniform grains have sizes up to hundreds of nanometres. These structural characters are promising for achieving high performance in phototransistors. As shown in Fig. 1e, the film surface was also characterized using $\mathrm{AFM}$, and the root-mean-square roughness is $\sim 10.5 \mathrm{~nm}$ in a typical scanning area of $5.0 \mu \mathrm{m} \times 5.0 \mu \mathrm{m}$. The three-dimensional AFM image in the inset of Fig. 1e further demonstrates the smooth surface of the perovskite film.

Phototransistor characterization. Figure 2a shows a representative set of the transfer characteristics, which are the drain current versus gate voltage $\left(I_{\mathrm{DS}}-V_{\mathrm{GS}}\right)$ data, of a bottom-gate top-contact $\mathrm{CH}_{3} \mathrm{NH}_{3} \mathrm{PbI}_{3}$ phototransistor. The devices were measured both in the dark and under white-light illumination (power density: $10 \mathrm{~mW} \mathrm{~cm}^{-2}$ ) at the drain voltages $\left(V_{\mathrm{DS}}\right)$ of -30 and $30 \mathrm{~V}$. An ambipolar high performance can be clearly observed in the transfer characteristics under light illumination, and the $\mathrm{V}$ shape of the transfer curves is similar to those of previous reports on ambipolar transistors ${ }^{51-56}$. The current of the illuminated channel can reach $0.1 \mathrm{~mA}$. In contrast, for the transfer characteristics measured under the dark condition, $I_{\mathrm{DS}}$, remains below $0.5 \mathrm{nA}$.

Figure $2 \mathrm{~b}, \mathrm{c}$ shows the plots of $I_{\mathrm{DS}}^{1 / 2}$ and $I_{\mathrm{DS}}$ as functions of $V_{\mathrm{GS}}$ for the perovskite phototransistor measured under light illumination. The plots appear linear for a large range of $V_{\mathrm{GS}}$ for both 




C

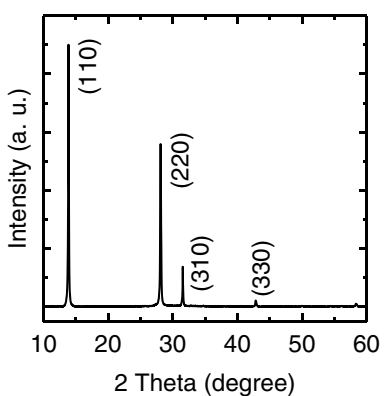

d
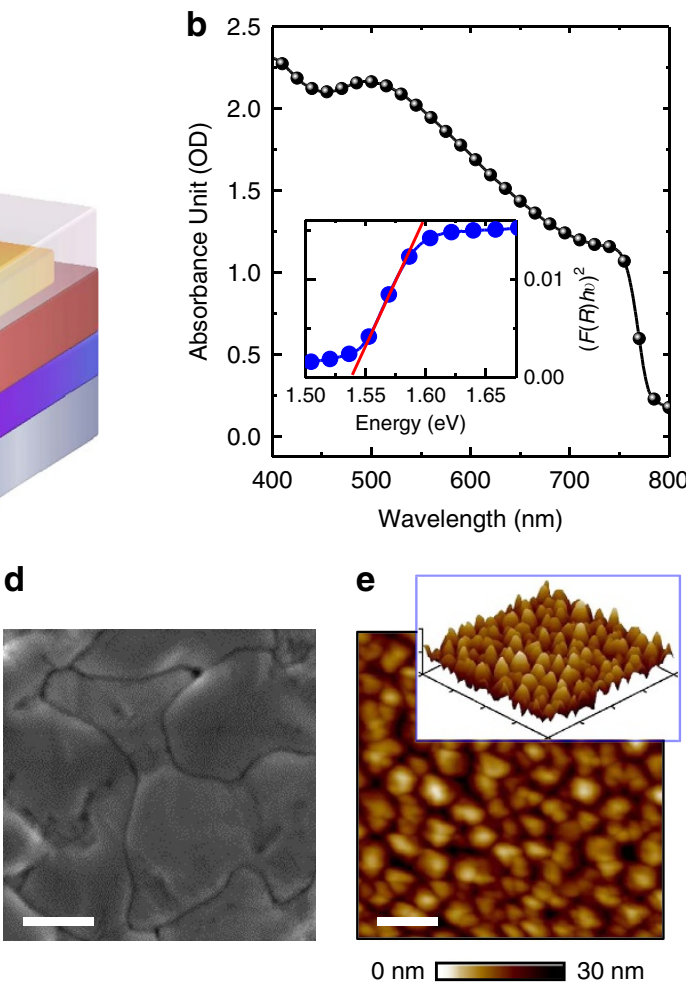

Figure 1 | Hybrid perovskite phototransistors. (a) Schematic of the phototransistor with a channel of hybrid perovskite $\mathrm{CH}_{3} \mathrm{NH}_{3} \mathrm{Pbl}_{3}$. (b) $\mathrm{Ultraviolet-}$ visible absorption of the 100-nm $\mathrm{CH}_{3} \mathrm{NH}_{3} \mathrm{Pbl}_{3}$ film. The inset shows a direct bandgap of $\sim 1.53 \mathrm{eV}$. (c) X-ray diffraction spectrum of the $\mathrm{CH}_{3} \mathrm{NH}_{3} \mathrm{Pbl}{ }_{3}$ film. (d) Top-view SEM image of the perovskite film. Scale bar, $0.5 \mu \mathrm{m}$. (e) Tapping-mode AFM height image of the perovskite film. Scale bar, $1.0 \mu \mathrm{m}$. Inset: the corresponding three-dimensional topographic image.
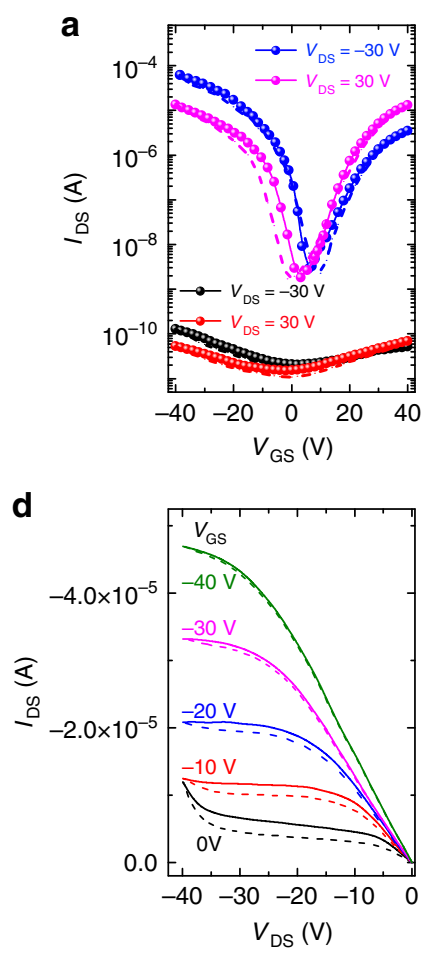


Figure 2 | Ambipolar characteristics of the hybrid perovskite phototransistors. (a) Transfer characteristics of a perovskite-based phototransistor in the dark (black and red symbols) and under light illumination (blue and magenta symbols). (b,c) Representation of the transfer characteristics of p-channel and n-channel behaviours, respectively, under light illumination. (d,e) Respective output properties of the device under light condition. (f) Output curves of the phototransistor in the dark condition. Solid and dashed curves were measured during forward and backward sweepings, respectively. 
p- and n-type transports. The field-effect mobility $(\mu)$ and threshold voltage $\left(V_{\mathrm{TH}}\right)$ can be extracted using the saturated $I_{\mathrm{DS}}$ versus $V_{\mathrm{GS}}$ relationship ${ }^{52,53}$ :

$$
I_{\mathrm{GS}}=\frac{W}{2 L} C_{\mathrm{i}} \mu\left(V_{\mathrm{GS}}-V_{\mathrm{TH}}\right)^{2}
$$

where $W, L$ and $C_{\mathrm{i}}$ are the channel width, the channel length and the gate capacitance per unit area, respectively. Accordingly, the photo-induced hole and electron mobilities are derived as 0.18 and $0.17 \mathrm{~cm}^{2} \mathrm{~V}^{-1} \mathrm{~s}^{-1}$, respectively, in the saturation region. Thus, it is clear that under light illumination the perovskite-based phototransistor exhibits ambipolar behaviour with balanced hole and electron mobilities.

Under light illumination, the output characteristics (that is, $I_{\mathrm{DS}}$ versus $V_{\mathrm{DS}}$ data at different $V_{\mathrm{GS}}$ ) obtained for the device operating in the hole-enhancement and electron-enhancement modes are displayed in Fig. 2 d,e, respectively. At low $V_{\mathrm{GS}}$, the device exhibits ambipolar transport with diode-like currentvoltage $(I-V)$ characteristics; however, at high $V_{\mathrm{GS}}$, unipolar transport with standard linear-to-saturation $I-V$ transistor characteristics was observed. Figure $2 f$ shows the output characteristics of the phototransistor measured in the dark. It can be clearly seen that there is no obvious field effect, and $I_{\mathrm{DS}}$ remains at the level of $10^{-10} \mathrm{~A}$, which is consistent with the transfer characteristics.

For measurements performed in the dark, as shown in Fig. 2a, $I_{\mathrm{DS}}$ remains less than $0.5 \mathrm{nA}$ when $V_{\mathrm{GS}}$ increases from -40 to $+40 \mathrm{~V}$, and the obtained on/off ratio is less than 10 . In contrast, regarding device performance under light illumination, the on current is significantly enhanced to $10^{-4} \mathrm{~A}$, while the off current also increases to $2.0 \times 10^{-9} \mathrm{~A}$. Furthermore, the on/off ratios under illumination are boosted to $3.32 \times 10^{4}$ for p-type and $8.76 \times 10^{3}$ for $n$-type transports. The significant gate-tuning effect on illumination with respect to the dark measurements implies that the photo-excited carriers dominate the channel transport; thus, the device has potential for use in other photoelectronic applications such as photosensors.

Furthermore, it should be noted that both the transfer curves and the output curves exhibit weak but notable hysteresis effects (Fig. 2), which were also reported for solar cells, memristors and light-emitting field-effect transistors on the basis of hybrid perovskites $^{31,57-59}$. One origin of the hysteresis effects was speculated to be the screening effects arisen from the fieldinduced drift of methylammonium cations ${ }^{59}$. In addition, charge traps and surface dipoles at the untreated semiconductordielectric interface may also attribute to the hysteresis effect ${ }^{53}$. In Fig. 2, the hysteresis effect in the phototransistor operation is not substantial, which is presumably a result of the high quality of the perovskite films.

To examine the effect of the device structure, we also fabricated a bottom-gate bottom-contact perovskite phototransistor (schematic shown in Supplementary Fig. 2). Supplementary Fig. 3 shows the ambipolar transfer characteristics of the devices under light illumination, which is similar to that of the bottom-gate topcontact devices. In this particular device, both the electron and hole mobilities were measured as $0.17 \mathrm{~cm}^{2} \mathrm{~V}^{-1} \mathrm{~s}-1$, suggesting a very balanced ambipolar transport under light illumination. These results reveal that the ambipolar performance of phototransistors is an intrinsic property of $\mathrm{CH}_{3} \mathrm{NH}_{3} \mathrm{PbI}_{3}$ and is independent of the device architecture.

Photoresponsivity $(R)$ is the key parameter for evaluating the performance of phototransistors, and its value can be obtained using transfer characteristics. $R$ is given by the following equation:

$$
R=\frac{I_{\text {light }}-I_{\text {dark }}}{E_{\text {light }}}
$$

where $I_{\text {light }}$ and $I_{\text {dark }}$ stand for the drain currents under light illumination and in the dark, respectively, and $E_{\text {light }}$ is the power of incident illumination. $R$ as a function of $V_{\mathrm{GS}}$ is shown in Fig. 3a. The maximum $R$ value of $320 \mathrm{~A} \mathrm{~W}^{-1}$ in the On state $\left(V_{\mathrm{GS}}=-40 \mathrm{~V}\right)$ was obtained at a power density of $10 \mathrm{~mW} \mathrm{~cm}^{-2}$. We also examined the phototransistors with various perovskite film thicknesses (shown in Supplementary Fig. 4), and we found that the performance of devices with the active layer thickness of $\sim 100 \mathrm{~nm}$ is optimal. Note that this parameter achieved in perovskite phototransistors is substantially higher than those of most other reported functional materials ${ }^{38,40,42-45,47,48}$. For example, phototransistors based on organic semiconductors and hybrid materials were reported with $R$ values typically below $1.0 \mathrm{~A} \mathrm{~W}^{-1}$ (ref. 45). This superb performance of hybrid perovskites in phototransistors can be attributed to their excellent light absorption properties, extremely low dark current and high photocurrent.

The external quantum efficiency (EQE) and photoresponsivity $(R)$ as the function of wavelength in our phototransistor are shown in Fig. 3b. The device exhibits a broad photoresponse range from 400 to $800 \mathrm{~nm}$, and its maximum EQE is approximately $80 \%$. Moreover, the device shows high $R$ values in the wavelength range of $400-750 \mathrm{~nm}$, and hence it is suitable for visible-light broadband photodetection. In addition, we found that the spectral sensitivities of the phototransistor are mainly determined by the absorption spectra of the perovskite film (Fig. 1b).

$\mathrm{CH}_{3} \mathrm{NH}_{3} \mathrm{PbI}_{3-x} \mathrm{Cl}_{x}$-based phototransistors. It was reported that $\mathrm{Cl}$ might act as a crystallization-retarding and -directing agent ${ }^{60}$, which benefits the growth of perovskite domains and thus improves the transport properties of the perovskite films ${ }^{21,22}$. Therefore, we fabricated mixed-halide perovskite $\mathrm{CH}_{3} \mathrm{NH}_{3} \mathrm{PbI}_{3-x} \mathrm{Cl}_{x}$-based phototransistors. Indeed, we found
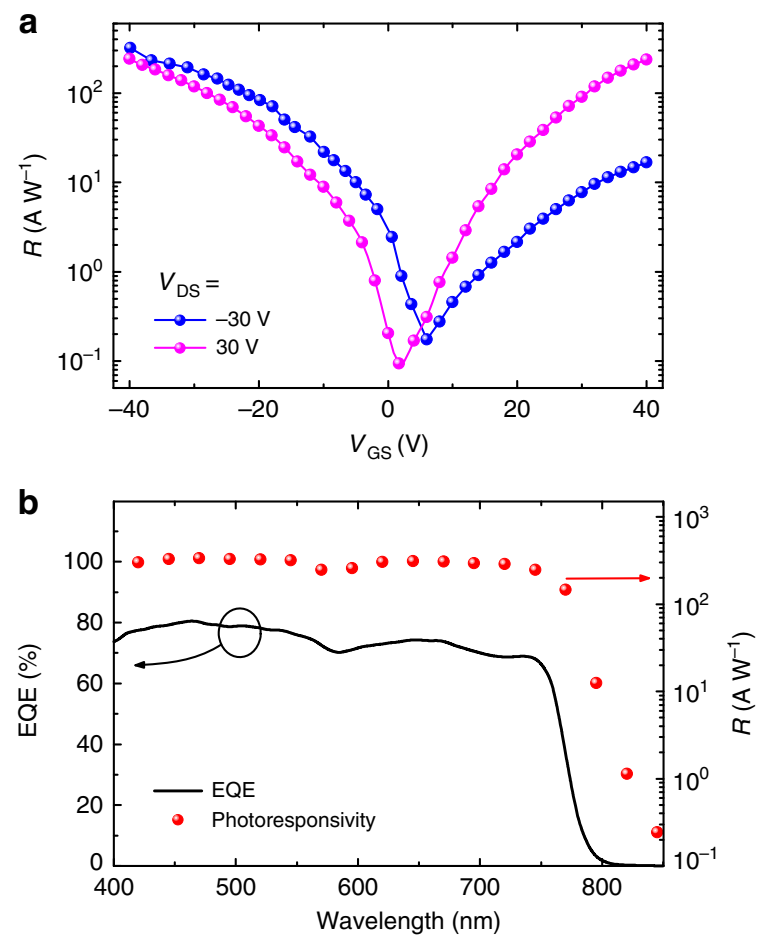

Figure 3 | Performance of the perovskite phototransistors.

(a) Photoresponsivity $(R)$ characteristics of the $\mathrm{CH}_{3} \mathrm{NH}_{3} \mathrm{Pbl}_{3}$ phototransistor under white-light illumination (power density = $10 \mathrm{~mW} \mathrm{~cm}^{-2}$ ). (b) EQE and $R$ of the hybrid perovskite photodetector at different wavelength and a $V_{D S}$ of $-30 \mathrm{~V}$. 
that the presence of $\mathrm{Cl}$ improves the surface smoothness of the perovskite films (Supplementary Fig. 5). The transfer characteristics of the $\mathrm{CH}_{3} \mathrm{NH}_{3} \mathrm{PbI}_{3-} \mathrm{Cl}_{x}$-based phototransistor in dark and light conditions are shown in Fig. 4a. Under light illumination $\left(10 \mathrm{~mW} \mathrm{~cm}^{-2}\right)$, the device shows clear ambipolar behaviour, similar to that of $\mathrm{CH}_{3} \mathrm{NH}_{3} \mathrm{PbI}_{3}$-based devices. As shown in Fig. $4 \mathrm{~b}, \mathrm{c}$, the slopes of $I_{\mathrm{DS}}^{1 / 2}$ versus $V_{\mathrm{GS}}$ are linear for a large range of $V_{\mathrm{GS}}$ for both p-type and n-type transports, which demonstrates the high quality of our phototransistors. On the basis of equation (1), the obtained mobilities of photoinduced holes and electrons are 1.24 and $1.01 \mathrm{~cm}^{2} \mathrm{~V}^{-1} \mathrm{~s}^{-1}$, respectively. However, unlike the case of $\mathrm{CH}_{3} \mathrm{NH}_{3} \mathrm{PbI}_{3}$ phototransistors, $I_{\mathrm{DS}}$ in $\mathrm{CH}_{3} \mathrm{NH}_{3} \mathrm{PbI}_{3}{ }_{-x} \mathrm{Cl}_{x}$ devices can reach $10 \mathrm{nA}$ under the dark condition, and the hole and electron mobilities are $1.62 \times 10^{-4}$ and $1.17 \times 10^{-4} \mathrm{~cm}^{2} \mathrm{~V}^{-1} \mathrm{~s}^{-1}$, respectively (Supplementary Fig. 6). These results obtained under the dark condition imply that the $\mathrm{CH}_{3} \mathrm{NH}_{3} \mathrm{PbI}_{3-} \mathrm{Cl}_{x}$ channels have substantially higher conductivity and mobility than the $\mathrm{CH}_{3} \mathrm{NH}_{3} \mathrm{PbI}_{3}$ ones. As shown in Supplementary Fig. 7, the maximum $R$ value of the $\mathrm{CH}_{3} \mathrm{NH}_{3} \mathrm{PbI}_{3-x} \mathrm{Cl}_{x}$ phototransistor is $\sim 47 \mathrm{~A} \mathrm{~W}^{-1}$ at $V_{\mathrm{GS}}=-40 \mathrm{~V}$. The lower $R$ of the $\mathrm{CH}_{3} \mathrm{NH}_{3} \mathrm{PbI}_{3-x} \mathrm{Cl}_{x}$ phototransistor compared with that of the $\mathrm{CH}_{3} \mathrm{NH}_{3} \mathrm{PbI}_{3}$ phototransistor is primarily because of its higher dark current. Nevertheless, this $R$ value is still comparable to the highest ones reported for other functional materials $s^{38,40,42-45,47,48}$.

Characterization of photocurrent response. Fast response to optical signals, which is a result of efficient charge transport and collection, is critical for optoelectronic devices. The time-dependent photocurrent was recorded when the white light $\left(10 \mathrm{~mW} \mathrm{~cm}^{-2}\right)$ was turned on and off regularly. Figure 5a shows the response of photocurrent to optical pulses at a time interval of $0.5 \mathrm{~s}$ when the device is biased at $V_{\mathrm{DS}}=-30 \mathrm{~V}$ and $V_{\mathrm{GS}}=-30 \mathrm{~V}$. We found that the dynamic photoresponse of the perovskite phototransistors was stable and reproducible. The photocurrent quickly increases as soon as the light is turned on and then drops to the original value when the light is turned off, indicating that the device functions as a good light-activated switch.

Figure $5 \mathrm{~b}$ shows the temporal photocurrent response of the perovskite phototransistor. The measured switching times for the rise ( $I_{\mathrm{DS}}$ increasing from 0 to $80 \%$ of the peak value) and decay ( $I_{\mathrm{DS}}$ decreasing from the peak value to $10 \%$ ) of the photocurrent are $\sim 6.5$ and $5.0 \mu \mathrm{s}$, respectively, indicating an ultrafast response speed. The decay time of the photodetector has previously been estimated as the carrier recombination time (lifetime, $\left.\tau_{\text {life }}\right)^{39,41,43}$. Recently, using a solar-cell-type photodetector, Dou et al. obtained response times below $200 \mathrm{~ns}$ (ref. 26). In fact, photoinduced electron-hole pairs in the pristine perovskite recombine within a few picoseconds (that is, within the lifetime of the photoexcited electrons $)^{30}$. However, in the presence of positive (negative) gate voltages, the photo-generated electrons (holes) are accumulated in the channel and acquire a higher mobility, while the other type of charges remain trapped in the perovskite channel. Thus, the recombination of the photo-excited electronhole pairs in the perovskite channel is reduced, resulting in increased carrier lifetime $\left(\tau_{\text {life }}\right)^{43,61}$. Nevertheless, the temporal photocurrent responses of our perovskite phototransistors are still substantially faster than those of most organic, quantum dot and hybrid photodetectors (typically in the order of milliseconds) $)^{36,41-49}$.

Figure $5 \mathrm{c}$ shows the characteristics of photo-switched channel current at $V_{\mathrm{DS}}=-30 \mathrm{~V}$ and various $V_{\mathrm{Gs}}$. As shown, on light illumination, a larger $V_{\mathrm{GS}}$ can induce a more significant increase in photocurrent. In particular, the photocurrent is $\sim 2.76 \times 10^{-9} \mathrm{~A}$ at $V_{\mathrm{GS}}=0 \mathrm{~V}$, whereas it dramatically increases to $1.21 \times 10^{-5} \mathrm{~A}$ at $V_{\mathrm{GS}}=-40 \mathrm{~V}$. These results demonstrate that the switching of the photocurrent could be tailored to a large degree using the gate voltages, enabling highly tunable photodetection.

Device stability. To enhance the stability of perovskite phototransistors, we coated some bottom-gate top-contact devices with PMMA-protective layers (noted as Device-P). These devices were stored under ambient conditions without isolation from exposures to atmospheric air and moisture. Previous lines of work on perovskite solar cells have demonstrated that coating the PMMAprotective layer is an effective strategy to improve the ambient stability of perovskites by forming kinetic barriers against the diffusion of moisture and/or atmospheric oxygen ${ }^{21}$. Under light illumination, the transfer curves of a device immediately following fabrication and after storing under ambient conditions for 60 days are essentially the same, except slight decreases in the channel current (shown in Fig. 6a), revealing excellent device stability. In contrast, the unprotected devices without the PMMA layer (noted as Device-U) exhibited sustantially weaker stability. Figure $6 \mathrm{~b}$ shows the transfer characteristics of a newly fabricated Device- $U$, which are similar to those of Device-P. The inset of Fig. $6 \mathrm{~b}$ shows the transfer curve of Device- $U$ that had been stored under ambient conditions for 60 days. Notably, the device showed $I_{\mathrm{DS}}$ of only $\sim 10^{-8} \mathrm{~A}$ at $V_{\mathrm{GS}}=-40 \mathrm{~V}$, which is nearly $10^{4}$-fold lower than the $I_{\mathrm{DS}}$ of the newly fabricated Device-U. Figure $6 \mathrm{c}$ shows the mobility and on/off ratio of the Device-P measured at different intervals over a period of 60 days. No apparent statistical variations in the mobilities or on/off ratio were observed, confirming the excellent stability of the encapsulated phototransistors. For the Device-U (shown in the inset of
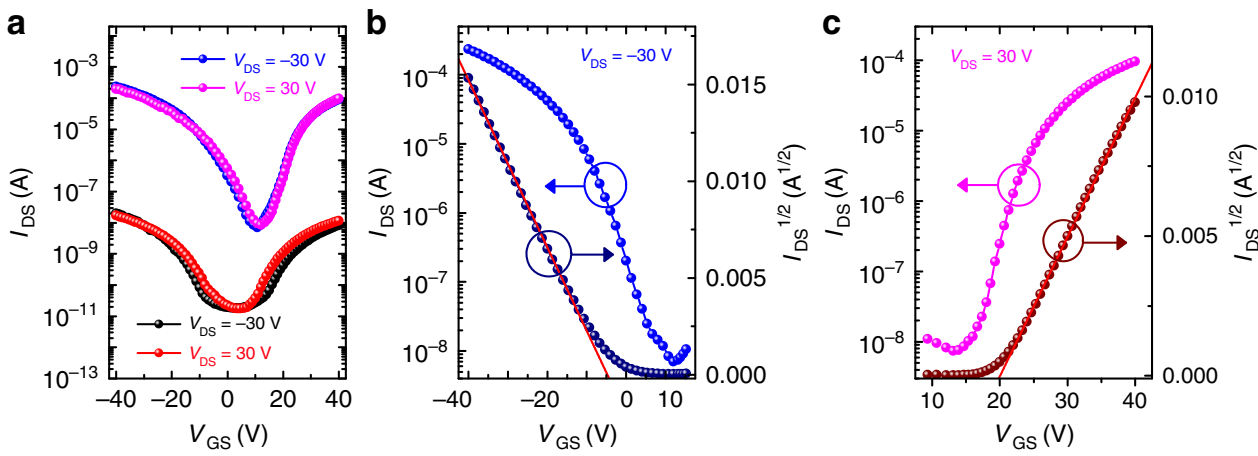

Figure 4 | Characteristics of the $\mathbf{C H}_{3} \mathbf{N H}_{3} \mathbf{P b l}_{3}{ }_{-} \mathbf{C l}_{\mathbf{x}}$-based phototransistors. (a) Transfer curves of the $\mathrm{CH}_{3} \mathrm{NH}_{3} \mathrm{Pbl}_{3-x} \mathrm{Cl}_{x}$ phototransistor in the dark (black and red symbols) and under light illumination (blue and magenta symbols). (b,c) Representation of the transfer characteristics of $\mathrm{p}$-type and $\mathrm{n}$-type behaviours, respectively, under light illumination. 

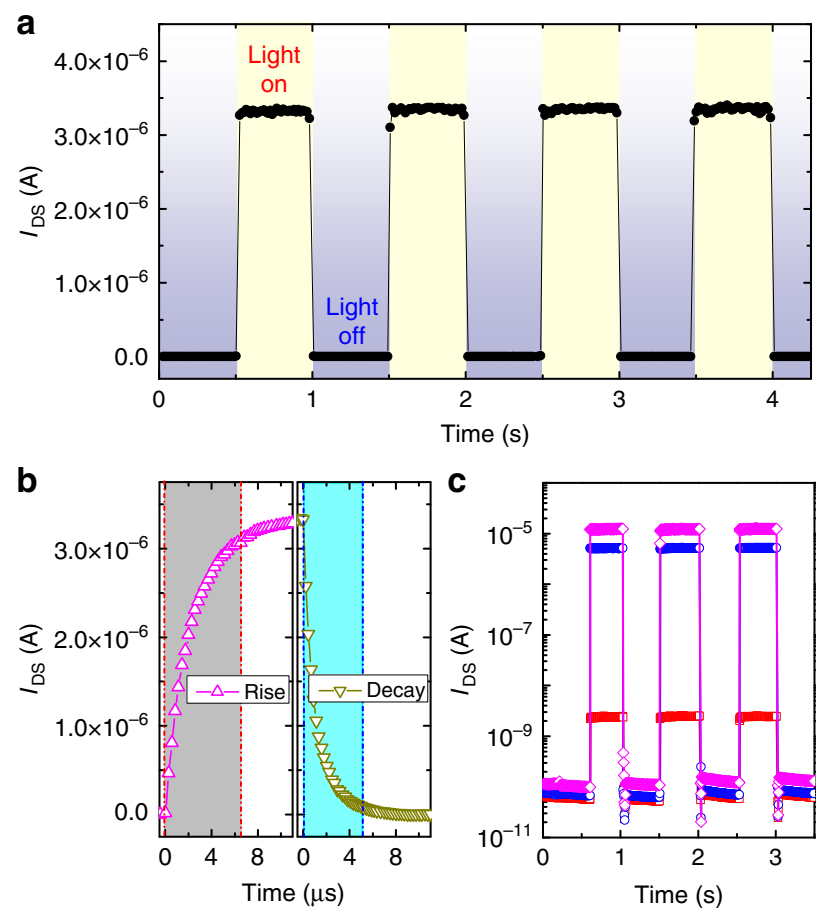

Figure 5 | Photocurrent response of the perovskite phototransistors.

(a) Photocurrent responses of the phototransistors on light illumination showing time-dependent photosensitivity with a time interval of $0.5 \mathrm{~s}$ at $V_{\mathrm{GS}}=-30 \mathrm{~V}$ and $V_{\mathrm{DS}}=-30 \mathrm{~V}$. (b) Temporal photocurrent responses highlighting a rise time of $6.5 \mu \mathrm{s}$ and a decay time of $5.0 \mu \mathrm{s}$. (c) Gate voltage-dependent photoresponses measured at $V_{D S}=-30 \mathrm{~V}$. The device was measured at $V_{\mathrm{GS}}$ of $\mathrm{OV}$ (red squares), $-30 \mathrm{~V}$ (blue circles) and $-40 \mathrm{~V}$ (magenta diamonds).
Fig. 6c), both the mobility and the on/off ratio declined continuously during 60 days of storage. However, it should be mentioned that the performance of Device- $U$ changed very little over the first 7 days, indicating that unprotected devices must be measured quickly to achieve reproducible data.

High reproducibility and stability are critical for photoelectronic devices and their integrations in real-world applications. Figure $6 \mathrm{~d}$ shows the distributions of hole mobility for both PMMA-protected and -unprotected as-fabricated devices. More than $70 \%$ of the Device-P group (20 devices) show hole mobility ranging from 0.13 to $0.19 \mathrm{~cm}^{2} \mathrm{~V}^{-1} \mathrm{~s}^{-1}$. However, among the 20 devices in the Device- $U$ group, there are notable fluctuations of mobility values: some are similar to Device-P, while others are even below $9 \times 10^{-2} \mathrm{~cm}^{2} \mathrm{~V}^{-1} \mathrm{~s}^{-1}$. The perovskite phototransistors without the PMMA layer often exhibit low reproducibility, primarily because of their high sensitivity towards moisture, room light and other factors under ambient conditions. Thus, coating PMMA-protective layers should be considered as a general protocol for enhancing device stability and reproducibility.

\section{Discussion}

In this work, ambipolar phototransistors based on solutionprocessed hybrid perovskites were fabricated and characterized. Owing to the superior optical and electronic properties of hybrid perovskites, our solution-processed phototransistors demonstrated high performances and tunability. Under light illumination, these devices exhibit reliable high performance with balanced carrier mobilities and on/off ratios of $\sim 10^{4}$ for both p- and n-type transports. Remarkably, the phototransistors show excellent figures-of-merit such as excellent photoresponsivity $\left(320 \mathrm{~A} \mathrm{~W}^{-1}\right)$ and ultrafast response speed (less than $\left.10 \mu \mathrm{s}\right)$.

In such phototransistors, both light illumination and gate bias can be used to modulate the transport of semiconducting a


b

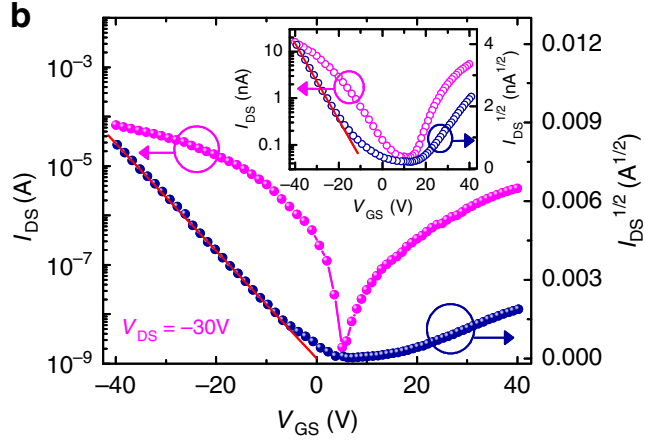

d

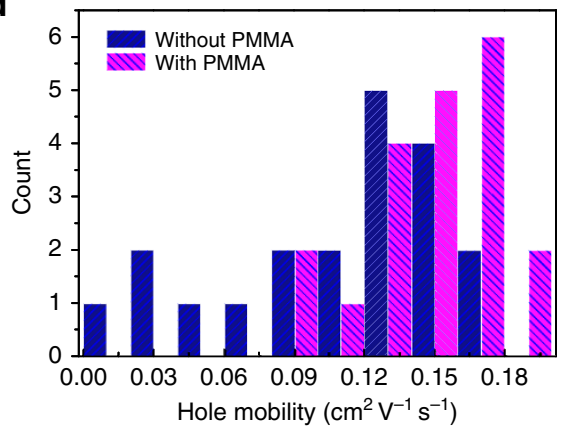

Figure 6 | Stability and reproducibility of the perovskite phototransistors. (a) Transfer curves under light illumination of the Device-P (with the PMMAprotective layer) immediately following fabrication and after storing under ambient conditions for 60 days. (b) Transfer characteristics under light illumination of the as-fabricated Device-U (without PMMA-protective layer). Inset, data measured after storing under ambient conditions for 60 days. (c) Mobility and on/off ratio of Device-P measured during 60 days of storage under ambient conditions. Stability data of Device- $U$ are also shown in the inset for comparison. (d) Histogram of the hole mobilities measured on 20 devices with the PMMA-protective layer and 20 devices without the protective layer. 
perovskite channels. Through the capacitive coupling, the gate bias is expected to effectively separate the photo-generated holes and electrons, increasing their recombination time, equivalently $\tau_{\text {life }}$ (ref. 43,61). The photoconductive gain $(G)$, that is, the number of carriers collected per photo-induced carrier, is given by the equation:

$$
G=\frac{\tau_{\text {life }}}{\tau_{\text {tran }}}=\frac{\tau_{\text {life }}}{L^{2} / \mu \cdot V_{\mathrm{DS}}}
$$

where $\tau_{\text {tran }}$ is the carrier transit time $e^{39,41-43}$. For our devices with mobility in the range of $0.2-2.0 \mathrm{~cm}^{2} \mathrm{~V}^{-1} \mathrm{~s}^{-1}, G$ is estimated to be $\sim 10-10^{2}$. Through biasing the gate terminal, our phototransistor architecture is advantageous for enhancing the photoresponse.

Furthermore, according to equation (3), the device performance should also benefit from high carrier mobility $(\mu)$. In our phototransistors, the field-effect hole/electron mobility was measured as $0.18 / 0.17 \mathrm{~cm}^{2} \mathrm{~V}^{-1} \mathrm{~s}^{-1}$ for $\mathrm{CH}_{3} \mathrm{NH}_{3} \mathrm{PbI}_{3}$ and 1.24 / $1.01 \mathrm{~cm}^{2} \mathrm{~V}^{-1} \mathrm{~s}^{-1}$ for $\mathrm{CH}_{3} \mathrm{NH}_{3} \mathrm{PbI}_{3-x} \mathrm{Cl}_{x}$, this is consistent with the $\mathrm{Cl}$-enhanced electron-hole diffusion lengths observed in previous lines of work on perovskite solar cells ${ }^{21,22}$. However, better phototransistor performance was achieved in the undoped $\mathrm{CH}_{3} \mathrm{NH}_{3} \mathrm{PbI}_{3}$ channel as a result of suppressed dark current. We should note that, although the field-effect mobility measured in our perovskite phototransistors is impressive for solutionprocessed materials, there is still room for improvements. Tailoring the deposition procedures and developing appropriate doping strategies are promising to optimize the transport properties of perovskite channels ${ }^{62,63}$.

Furthermore, according to equation (3), reducing the channel length $(L)$ is a straightforward way to improve the performance of phototransistors. In the present device structure, the channel length is $50 \mu \mathrm{m}$, which are much longer than the diffusion lengths of the carriers. Therefore, light-induced carriers are scattered many times by structural defects and grain boundaries before reaching the electrodes ${ }^{64,65}$. Much higher carrier mobility is expected in phototransistors with shorter channel lengths, which could further improve the phototransistor performance. Shrinking the channel dimensions may also help decrease the $V_{\mathrm{DS}}$ required for the device operation and reduce the energy consumption. Overall, our findings strongly support the use of hybrid perovskites as active materials in high-performance ambipolar phototransistors, and open new doors for employing such solution-processed perovskites in other photoelectronic applications.

\section{Methods}

Perovskite preparation and device fabrication. $\mathrm{CH}_{3} \mathrm{NH}_{3} \mathrm{I}$ was synthesized according to a previously reported procedure ${ }^{2,6,11}$. First, $24 \mathrm{ml}$ of methylamine (33 wt $\%$ in absolute ethanol, Sigma) and $10 \mathrm{ml}$ of hydroiodic acid (57 wt\% in water, Aldrich) were mixed to react in a $250-\mathrm{ml}$ round-bottomed flask at $0{ }^{\circ} \mathrm{C}$ for $2 \mathrm{~h}$ with stirring. The precipitate was recovered via evaporation at $50^{\circ} \mathrm{C}$ for $1 \mathrm{~h}$. The product, methylammonium iodide $\mathrm{CH}_{3} \mathrm{NH}_{3} \mathrm{I}$, was washed with diethyl ether by stirring the solution for $30 \mathrm{~min}$, which was repeated three times. The product was finally dried at $60^{\circ} \mathrm{C}$ in a vacuum oven for $24 \mathrm{~h}$. The perovskite films were prepared according to the vapour-assisted solution process ${ }^{11}$. The heavily n-doped $\mathrm{Si}$ wafers with $300-\mathrm{nm} \mathrm{SiO}_{2}$ surface layers (capacitance of $15 \mathrm{nF} \mathrm{cm}^{-2}$ ) were used as the substrates. They were successively cleaned with diluted detergent, rinsed with deionized water, acetone and ethanol and dried with dry nitrogen. After the oxygen plasma treatment, the solution of $0.3 \mathrm{M} \mathrm{PbI}_{2}$ or $\mathrm{PbCl}_{2}$ (Sigma) in

dimethylformamide was spin-coated on the cleaned Si substrates at 5,000 r.p.m. for $40 \mathrm{~s}$ and dried at $110^{\circ} \mathrm{C}$ for $15 \mathrm{~min} . \mathrm{CH}_{3} \mathrm{NH}_{3} \mathrm{I}$ powders were spread around the $\mathrm{PbI}_{2}$ - or $\mathrm{PbCl}_{2}$-coated substrates, and a Petri dish was placed over the samples. The substrates were heated at $150^{\circ} \mathrm{C}$ for $8 \mathrm{~h}$. After cooling, the as-prepared films were washed with isopropanol and dried at $65^{\circ} \mathrm{C}$ for $5 \mathrm{~min}$. Finally, Ti/Au $(5 \mathrm{~nm} / 80 \mathrm{~nm})$ source (S) and drain (D) electrodes were deposited via thermal evaporation through a shadow mask, defining a channel length $(L)$ of $50 \mu \mathrm{m}$ and a channel width $(W)$ of $1,000 \mu \mathrm{m}$. Furthermore, the fabricated devices were annealed in a glove box at $50-60^{\circ} \mathrm{C}$ for $10 \mathrm{~min}$ to reduce the charge traps and improve the contact between the active layer and the S/D electrodes ${ }^{66}$. The bottom-gate bottom- contact devices were fabricated following similar procedures, except that Au S/D electrodes were deposited on the Si substrates before spin-coating the $\mathrm{PbI}_{2}$ or $\mathrm{PbCl}_{2}$ solution. To improve device stability, thin layers of PMMA (average molecular weight $\sim 350,000$ by Gel Permeation Chromatography, Sigma-Aldrich) were spincoated on the surfaces of the perovskite films at 8,000 r.p.m. for $60 \mathrm{~s}$.

Measurements and experimental set-up. Perovskite film thickness was assessed using the scratch method via AFM (Bruker Dimension ICON). X-ray diffraction patterns of the perovskite films were recorded using a Bruker D8 ADVANCE diffractometer with $\mathrm{Cu} \mathrm{K \alpha}(\lambda=1.5406 \AA)$ radiation. A field-emission SEM (FEI Nova Nano 630) was used to acquire surface SEM images. In addition, the morphology of the perovskite films was determined via AFM measurements in the tapping mode. The absorption spectra were measured using an Agilent Cary 6000i UV-Visible-NIR spectrometer. The devices $I-V$ measurements were performed using a Keithley 4200 Semiconductor Parametric Analyzer and a Signotone Micromanipulator S-1160 probe station. A light-emitting diode (white light, $10 \mathrm{~mW} \mathrm{~cm}^{-2}$ ) attached to the microscope of the probe station was used as the light source. During the measurements, the samples were kept at room temperature in the ambient atmosphere. The EQE of the device was measured using an Oriel IQE-200 measurement system.

\section{References}

1. Kojima, A., Teshima, K., Shirai, Y. \& Miyasaka, T. Organometal halide perovskites as visible-light sensitizers for photovoltaic cells. J. Am. Chem. Soc 131, 6050-6051 (2009).

2. Im, J.-H., Lee, C.-R., Lee, J.-W., Park, S.-W. \& Park, N.-G. 6.5\% efficient perovskite quantum-dot-sensitized solar cell. Nanoscale 3, 4088-4093 (2011).

3. Kim, H.-S. et al. Lead iodide perovskite sensitized all-solid-state submicron thin film mesoscopic solar cell with efficiency exceeding 9\%. Sci. Rep. 2, 591 (2012).

4. Lee, M. M., Teuscher, J., Miyasaka, T., Murakami, T. N. \& Snaith, H. J. Efficient hybrid solar cells based on meso-superstructured organometal halide perovskites. Science 338, 643-647 (2012).

5. Etgar, L. et al. Mesoscopic $\mathrm{CH}_{3} \mathrm{NH}_{3} \mathrm{PbI}_{3} / \mathrm{TiO}_{2}$ heterojunction solar cells. J. Am. Chem. Soc. 134, 17396-17399 (2012).

6. Burschka, J. et al. Sequential deposition as a route to high-performance perovskite-sensitized solar cells. Nature 499, 316-319 (2013).

7. Zhao, Y. \& Zhu, K. Charge transport and recombination in perovskite $\mathrm{CH}_{3} \mathrm{NH}_{3} \mathrm{PbI}_{3}$ sensitized $\mathrm{TiO}_{2}$ solar cells. J. Phys. Chem. Lett. 4, 2880-2884 (2013).

8. Heo, J. H. et al. Efficient inorganic-organic hybrid heterojunction solar cells containing perovskite compound and polymeric hole conductors. Nat. Photon 7, 486-491 (2013).

9. McGehee, M. D. Materials science: fast-track solar cells. Nature 501, 323-325 (2013).

10. Liu, M., Johnston, M. B. \& Snaith, H. J. Efficient planar heterojunction perovskite solar cells by vapour deposition. Nature 501, 395-398 (2013).

11. Chen, Q. et al. Planar heterojunction perovskite solar cells via vapor-assisted solution process. J. Am. Chem. Soc. 136, 622-625 (2014).

12. Liu, D. \& Kelly, T. L. Perovskite solar cells with a planar heterojunction structure prepared using room-temperature solution processing techniques. Nat. Photon 8, 133-138 (2014).

13. Zhou, H. et al. Interface engineering of highly efficient perovskite solar cells. Science 345, 542-546 (2014).

14. Weber, $\mathrm{D}$. $\mathrm{CH}_{3} \mathrm{NH}_{3} \mathrm{PbX}_{3}$, ein $\mathrm{Pb}$ (II)-system mit kubischer perowskitstruktur. Z. Naturforsch. B 33, 1443-1445 (1978).

15. Mitzi, D. B. In Progress in Inorganic Chemistry, 1-121 (John Wiley \& Sons, Inc., 2007).

16. Kagan, C. R., Mitzi, D. B. \& Dimitrakopoulos, C. D. Organic-inorganic hybrid materials as semiconducting channels in thin-film field-effect transistors. Science 286, 945-947 (1999).

17. Stoumpos, C. C. et al. Semiconducting tin and lead iodide perovskites with organic cations: phase transitions, high mobilities, and near-infrared photoluminescent properties. Inorg. Chem. 52, 9019-9038 (2013).

18. De Wolf, S. et al. Organometallic halide perovskites: sharp optical absorption edge and its relation to photovoltaic performance. J. Phys. Chem. Lett. 5, 1035-1039 (2014).

19. Wehrenfennig, C. et al. High charge carrier mobilities and lifetimes in organolead trihalide perovskites. Adv. Mater. 26, 1584-1589 (2014).

20. Ponseca, C. S. et al. Organometal halide perovskite solar cell materials rationalized: ultrafast charge generation, high and microsecond-long balanced mobilities, and slow recombination. J. Am. Chem. Soc. 136, 5189-5192 (2014).

21. Stranks, S. D. et al. Electron-hole diffusion lengths exceeding 1 micrometer in an organometal trihalide perovskite absorber. Science 342, 341-344 (2013).

22. Xing, G. et al. Long-range balanced electron- and hole-transport lengths in organic-inorganic $\mathrm{CH}_{3} \mathrm{NH}_{3} \mathrm{PbI}_{3}$. Science 342, 344-347 (2013).

23. Deschler, F. et al. High photoluminescence efficiency and optically pumped lasing in solution-processed mixed halide perovskite semiconductors. J. Phys. Chem. Lett. 5, 1421-1426 (2014). 
24. Xing, G. et al. Low-temperature solution-processed wavelength-tunable perovskites for lasing. Nat. Mater. 13, 476-480 (2014).

25. Tan, Z.-K. et al. Bright light-emitting diodes based on organometal halide perovskite. Nat. Nanotechnol. 9, 687-692 (2014).

26. Dou, L. et al. Solution-processed hybrid perovskite photodetectors with high detectivity. Nat. Commun. 5, 5404 (2014)

27. Horváth, E. et al. Nanowires of methylammonium lead iodide (CH3NH3PbI3) prepared by low temperature solution-mediated crystallization. Nano Lett. 14, 6761-6766 (2014).

28. Dong, R. et al. High-gain and low-driving-voltage photodetectors based on organolead triiodide perovskites. Adv. Mater. 27, 1912-1918 (2015).

29. Guo, Y. et al. Air-stable and solution-processable perovskite photodetectors for solar-blind UV and visible light. J. Phys. Chem. Lett. 6, 535-539 (2015).

30. Lee, Y. et al. High-performance perovskite-graphene hybrid photodetector. Adv. Mater. 27, 41-46 (2015).

31. Chin, X. Y., Cortecchia, D., Yin, J., Bruno, A. \& Soci, C. Lead iodide perovskite light-emitting field-effect transistor. Nat. Commun. 6, 7383 (2015).

32. Decoster, D. \& Harari, J. (eds) Optoelectronic Sensors Vol. 1(Wiley-ISTE, 2009).

33. Sze, S. M. \& Ng, K. K. Physics of Semiconductor Devices Vol. 3(John Wiley \& Sons, 2007).

34. Luo, H., Chang, Y., Wong, K. S. \& Wang, Y. Ultrasensitive Si phototransistors with a punchthrough base. Appl. Phys. Lett. 79, 773-775 (2001).

35. Ogura, M. Hole injection type InGaAs-InP near infrared photo-FET (HI-FET). IEEE J. Quantum Electron. 46, 562-569 (2010).

36. Liu, X. et al. All-printable band-edge modulated $\mathrm{ZnO}$ nanowire photodetectors with ultra-high detectivity. Nat. Commun. 5, 4007 (2014).

37. Avouris, P., Freitag, M. \& Perebeinos, V. Carbon-nanotube photonics and optoelectronics. Nat. Photon 2, 341-350 (2008).

38. Konstantatos, G. et al. Ultrasensitive solution-cast quantum dot photodetectors. Nature 442, 180-183 (2006).

39. Konstantatos, G. \& Sargent, E. H. Nanostructured materials for photon detection. Nat. Nanotechnol. 5, 391-400 (2010).

40. Lee, J. S. et al. Band-like transport, high electron mobility and high photoconductivity in all-inorganic nanocrystal arrays. Nat. Nanotechnol. 6, 348-352 (2011).

41. Konstantatos, G. et al. Hybrid graphene-quantum dot phototransistors with ultrahigh gain. Nat. Nanotechnol. 7, 363-368 (2012).

42. Koppens, F. H. L. et al. Photodetectors based on graphene, other twodimensional materials and hybrid systems. Nat. Nanotechnol. 9, 780-793 (2014).

43. Park, S. et al. Significant enhancement of infrared photodetector sensitivity using a semiconducting single-walled carbon nanotube $/ \mathrm{C}_{60}$ phototransistor. Adv. Mater. 27, 759-765 (2015)

44. Tang, Q. et al. Photoswitches and phototransistors from organic singlecrystalline sub-micro/nanometer ribbons. Adv. Mater. 19, 2624-2628 (2007).

45. Baeg, K.-J., Binda, M., Natali, D., Caironi, M. \& Noh, Y.-Y. Organic light detectors: photodiodes and phototransistors. Adv. Mater. 25, $4267-4295$ (2013).

46. Yu, H., Bao, Z. \& Oh, J. H. High-performance phototransistors based on singlecrystalline n-channel organic nanowires and photogenerated charge-carrier behaviors. Adv. Funct. Mater. 23, 629-639 (2013).

47. Yin, Z. et al. Single-layer $\mathrm{MoS}_{2}$ phototransistors. ACS Nano 6, 74-80 (2012).

48. Zhang, W. et al. High-gain phototransistors based on a CVD $\mathrm{MoS}_{2}$ monolayer. Adv. Mater. 25, 3456-3461 (2013).

49. Zhang, W. et al. Role of metal contacts in high performance phototransistors based on $\mathrm{WSe}_{2}$ monolayers. ACS Nano 8, 8653-8661 (2014).

50. Zhang, F. et al. Ultrathin film organic transistors: precise control of semiconductor thickness via spin-coating. Adv. Mater. 25, 1401-1407 (2013).

51. Meijer, E. J. et al. Solution-processed ambipolar organic field-effect transistors and inverters. Nat. Mater. 2, 678-682 (2003).

52. Podzorov, V., Gershenson, M. E., Kloc, C. h., Zeis, R. \& Bucher, E. Highmobility field-effect transistors based on transition metal dichalcogenides. Appl. Phys. Lett. 84, 3301-3303 (2004).

53. Zaumseil, J. \& Sirringhaus, H. Electron and ambipolar transport in organic field-effect transistors. Chem. Rev. 107, 1296-1323 (2007).
54. Cornil, J., Brédas, J.-L., Zaumseil, J. \& Sirringhaus, H. Ambipolar transport in organic conjugated materials. Adv. Mater. 19, 1791-1799 (2007).

55. Fan, J. et al. High-performance ambipolar transistors and inverters from an ultralow bandgap polymor. Adv. Mater. 24, 2186-2190 (2012).

56. Bisri, S. Z., Piliego, C., Gao, J. \& Loi, M. A. Outlook and emerging semiconducting materials for ambipolar transistors. Adv. Mater. 26, 1176-1199 (2014).

57. Snaith, H. J. et al. Anomalous hysteresis in perovskite solar cells. J. Phys. Chem. Lett. 5, 1511-1515 (2014).

58. Shao, Y. et al. Origin and elimination of photocurrent hysteresis by fullerene passivation in $\mathrm{CH}_{3} \mathrm{NH}_{3} \mathrm{PbI}_{3}$ planar heterojunction solar cells. Nat. Commun. 5, 5784 (2014).

59. Xiao, Z. et al. Giant switchable photovoltaic effect in organometal trihalide perovskite devices. Nat. Mater. 14, 193-198 (2015).

60. $\mathrm{Yu}, \mathrm{H}$. et al. The role of chlorine in the formation process of " $\mathrm{CH}_{3} \mathrm{NH}_{3} \mathrm{PbI}_{3-\mathrm{x}} \mathrm{Cl}_{\mathrm{x}}$ " Perovskite. Adv. Funct. Mater. 24, 7102-7108 (2014).

61. Dutta, S. \& Narayan, K. S. Gate-voltage control of optically-induced charges and memory effects in polymer field-effect transistors. Adv. Mater. 16, 2151-2155 (2004).

62. Mitzi, D. B. et al. Structurally tailored organic - inorganic perovskites: optical properties and solution-processed channel materials for thin-film transistors. Chem. Mater. 13, 3728-3740 (2001).

63. Mitzi, D. B. et al. Hybrid field-effect transistor based on a low-temperature melt-processed channel layer. Adv. Mater. 14, 1772-1776 (2002).

64. Noel, N. K. et al. Enhanced photoluminescence and solar cell performance via Lewis base passivation of organic-inorganic lead halide perovskites. ACS Nano 8, 9815-9821 (2014).

65. Shkrob, I. A. \& Marin, T. W. Charge trapping in photovoltaically active perovskites and related halogenoplumbate compounds. J. Phys. Chem. Lett. 5, 1066-1071 (2014).

66. Gwinner, M. C. et al. Simultaneous optimization of light gain and charge transport in ambipolar light-emitting polymer field-effect transistors. Chem. Mater. 21, 4425-4433 (2009).

\section{Acknowledgements}

This work was supported by King Abdullah University of Science and Technology (KAUST).

\section{Author contributions}

F.L. performed the device fabrication, data collection and analysis. C.M. assisted in carrying out the film fabrication and characterizations, and W.H. assisted in the device performance measurements. T.W. planned and supervised the project. All authors discussed the results, and prepared and commented on the manuscript.

\section{Additional information}

Supplementary Information accompanies this paper at http://www.nature.com/ naturecommunications

Competing financial interests: The authors declare no competing financial interests.

Reprints and permission information is available online at http://npg.nature.com/ reprintsandpermissions/

How to cite this article: Li, F. et al. Ambipolar solution-processed hybrid perovskite phototransistors. Nat. Commun. 6:8238 doi: 10.1038/ncomms9238 (2015).

This work is licensed under a Creative Commons Attribution 4.0 International License. The images or other third party material in this article are included in the article's Creative Commons license, unless indicated otherwise in the credit line; if the material is not included under the Creative Commons license users will need to obtain permission from the license holder to reproduce the material. To view a copy of this license, visit http://creativecommons.org/licenses/by/4.0/ 